\title{
ELECTROMIOGRAPHIC SIGNAL RELIABILITY ANALYSIS DURING ISOMETRIC AND DYNAMIC ACTIONS PERFORMED IN DIFFERENT ENVIRONMENTS
}

\author{
Cristine Lima Alberton, Eduardo Marczwski da Silva, Marcus Peikriswili Tartaruga, Eduardo \\ Lusa Cadore, Márcio Eduardo Becker, Michel Arias Brentano, Tiago de Menezes Arrial, Luiz \\ Fernando Martins Kruel
}

\author{
Federal University of Rio Grande do Sul, Porto Alegre, RS, Brazil \\ E-mail: tinialberton@yahoo.com.br
}

\section{INTRODUCTION}

In attempt to reproduce the electromyographic signal (EMG) on land, investigations were performed during isometric and dynamic contractions. In aquatic environment, the research of Pöyhönen et al. (1999) was the unique found in literature that had analyzed the EMG signal reliability in maximal and submaximal isometric contractions. Independent of environment, the action type during the exercise may difficult the EMG signal reliability (Sbriccoli et al., 2003).

The objective of the present study was to analyze the EMG signal reliability of the vastus lateralis and biceps femoris muscles during isometric and dynamic actions performed in aquatic environment and on land.

\section{METHODS}

The study sample consisted of six young women $(22 \pm 1 \mathrm{yrs})$ water aerobics experts, that performed four experimental sessions ( 2 in aquatic environment and 2 on land).

In each experimental session, a maximal voluntary isometric contraction (MVIC) was performed on land for knee extensors and flexors. Subsequently, the dynamic exercise (Stationary running) was performed in aquatic environment (first week) and on land (second week) in three different cadences
(100, 80, and $60 \mathrm{bpm})$. The interval between each session in both environments was 24 to 48 hours.

Electrodes were placed on the belly of vastus lateralis (VL) and biceps femoris (BF) muscles with a $3-\mathrm{cm}$ center-to-center spacing. Transparent dressing was used to insulate electrodes for the water condition trials.

The EMG signals were registered with a 4channel EMG system (Miotool400 USB, Brazil), with a common mode rejection ratio $>110 \mathrm{~dB}$ and a sampling rate of $2000 \mathrm{~Hz}$ by channel. The filtering of the raw EMG was performed with a filter Butterworth type, with a bandwidth of $25-500 \mathrm{~Hz}$. The EMG data of each muscle were normalized by MVIC. The root mean square (rms) values were used to analyses.

Intertester reliability measurements were determined using Intraclass Correlation Coefficients (ICC) for rmsEMG values during MVIC and for normalized rmsEMG values during dynamic exercise. The significance level adopted was $p<0.05$ (SPSS vs 13.0).

\section{RESULTS AND DISCUSSION}

For isometric exercise, high ICC values were found for both muscles (VL: $\mathrm{ICC}=0.86$; $\mathrm{BF}$ : $\mathrm{ICC}=0.98$ ). However, for dynamic exercise high ICC values were 
found only in aquatic environment in cadence of $100 \mathrm{bpm}$ (see Table 1).

The results suggested an excellent reliability for $\mathrm{VL}$ and $\mathrm{BF}$ muscles activity during MVIC with short intervals of 24 and $48 \mathrm{hs}$. The high ICC found in stationary running, only at $100 \mathrm{bpm}$ in water, might be explained due to the wide use of this cadence in water aerobics routines.

However, some characteristics of dynamic exercise such as electrodes placement, control of the range of motion, and of the angular velocity can difficult their reliability in the other cadences in water and in all cadences on land. These difficults appears to be more related to the characteristic of the dynamic exercise than with the environment itself.

\section{SUMMARY}

Thus, in maximal voluntary isometric contraction on land and in stationary running at $100 \mathrm{bpm}$ in water was found a high reliability in contrast to other cadences in water and all cadences on land.

\section{REFERENCES}

Pöyhönen, T., Keskinen, K. L., Hautala, A., Savolainen, J., Mälkiä, E. (1999). Human isometric force production and electromyogram activity of knee extensor muscles in water and on dry land. Eur. $J$. Appl. Physiol., 80, 52-56.

Sbriccoli, P., Bazzucchi, I., Rosponi, A., Bernardi, M., Devito, G., Felici, F. (2003). Amplitude and spectral characteristics of bíceps brachii semg depend upon speed of isometric force generation. $J$. Electromyogr. Kinesiol., 13, 139-147.

Table 1 - Intraclass Correlation Coefficients (ICC) for normalized rmsEMG values during dynamic exercise.

\begin{tabular}{llcc}
\hline Muscle & Cadence & rmsEMG $(\%)-$ in water & rmsEMG(\%) - on land \\
\cline { 3 - 4 } & & ICC & ICC \\
\hline VL & $60 \mathrm{bpm}$ & 0.68 & 0.13 \\
& $80 \mathrm{bpm}$ & 0.29 & 0.04 \\
& $100 \mathrm{bpm}$ & $0.98^{*}$ & 0.02 \\
$\mathrm{BF}$ & $60 \mathrm{bpm}$ & 0.64 & 0.44 \\
& $80 \mathrm{bpm}$ & 0.64 & 0.34 \\
& $100 \mathrm{bpm}$ & $0.99^{*}$ & 0.13 \\
\hline
\end{tabular}

Note: $* \mathrm{p}<0.05$. 